\title{
BIBLIOTECAS PÚBLICAS: POLÍTICAS DO ESTADO DE MINAS GERAIS (1983-2012)
}

\author{
BIBLIOTECAS PÚBLICAS: POLÍTICAS DEL \\ ESTADO DE MINAS GERAIS
}

\author{
Marina Nogueira Ferraz* \\ Adriana Bogliolo Sirihal Duarte** \\ Mirian Ferreira Costa ${ }^{\star \star \star}$
}

\begin{abstract}
RESUMO
Introdução: Trata-se de uma pesquisa de cunho qualitativo que descreve e analisa as políticas para bibliotecas públicas de Minas Gerais, visando compreender os possíveis avanços e retrocessos destas políticas no período de 1983 a 2012. Justifica-se esta investigação na medida em que pesquisar as bibliotecas públicas dentro do contexto das políticas públicas poderá servir como um suporte importante para que os gestores públicos programem novas ações, contribuindo para o estudo do papel social da informação e das políticas culturais no campo da Ciência da Informação.
\end{abstract}

Objetivos: Tem como objetivos específicos identificar as políticas governamentais para bibliotecas públicas por meio de atos legais e documentos administrativos; conhecer a implementação real de tais políticas por meio de depoimentos e acompanhar os possíveis avanços ou retrocessos proporcionados pelas políticas implementadas para as bibliotecas públicas.

Metodologia: A metodologia utilizada foi a análise documental, por meio da análise de conteúdo dos documentos, e também a realização de entrevistas semi-estruturadas com gestores da Superintendência de Bibliotecas Públicas de Minas Gerais.

Resultados: Os dados foram classificados em categorias de análise, a saber: marcos legais, rede de bibliotecas, relação estado-União, relação estadosmunicípios, papel do bibliotecário, capacitação e eventos, comunicação, financiamento, Políticas de Estado ou de Governo e Plano Estadual do Livro e Leitura.

Conclusões: Ao final, verificou-se que as políticas para bibliotecas públicas em Minas Gerais têm avançado, ainda que timidamente, e que as políticas já

* Doutoranda em Ciência da Informação pela Escola de Ciência da Informação da Universidade Federal de Minas Gerais (UFMG). Bibliotecário na UFMG. E-mail: marina.nogueiraf@gmail.com

${ }^{*}$ Doutora em Ciência da Informação pela Universidade Federal de Minas Gerais (UFMG). Professora na Escola de Ciência da Informação da UFMG. E-mail: bogliolo@eci.ufmg.br

${ }^{\star \star \star}$ Graduada em Arquivologia pela Universidade Federal de Minas Gerais (UFMG). Email: mirianferreira.ufmg@gmail.com 
realizadas configuram-se, sobremaneira, como políticas de Governo, e não como políticas de Estado.

Palavras-chave: Biblioteca pública. Política pública. Minas Gerais.

\section{INTRODUÇÃO}

As mudanças sociais, econômicas e tecnológicas vividas nos tempos atuais na chamada Era da Informação ou Sociedade da Informação, têm trazido como consequência o desenvolvimento das tecnologias, o encurtamento das distâncias e, principalmente, a valorização da informação. Porém, mesmo diante do quadro de um mundo globalizado, a desigualdade de acesso à informação ainda persiste.

As bibliotecas públicas podem e devem desempenhar o papel de disseminadoras da informação e foram criadas para este fim. No entanto, ao longo de sua trajetória desempenharam papel de bibliotecas escolares, suprindo uma falta histórica no Brasil e no mundo, foram direcionadas por interesses políticos, e mais do que tudo, nunca receberam a devida atenção e reconhecimento como instituições, por excelência, democráticas e que servem como veículo para o desenvolvimento da cidadania e acesso ao conhecimento.

Ainda pouco frequentadas pela maioria da população, o papel das bibliotecas públicas vem passando por mudanças nas últimas décadas, voltando-se para um desempenho dinâmico, vivo, integrado às várias manifestações artísticas e atuando como importante instrumento de caráter social, que contribui para o diálogo e articulação da comunidade.

Machado e Suaiden (2013) comentam a crise vivida pelas bibliotecas públicas e apontam alguns caminhos como alternativas para superação, baseados no Manifesto da UNESCO para as bibliotecas públicas de 1994: 
O resgate da biblioteca pública corresponde ao seu resgate enquanto instituição indispensável à sociedade, no desenvolvimento da democracia e na formação de cidadãos conscientes e críticos. Uma unidade de informação que possibilite a educação permanente, fornecendo as condições básicas para uma aprendizagem contínua, e inclusão digital e social, além do desenvolvimento cultural dos indivíduos e dos grupos sociais, atuando como agente essencial para a promoção da paz e do bem-estar espiritual nas mentes dos homens e das mulheres (MACHADO; SUAIDEN, 2013, p. 1).

As bibliotecas públicas têm sido objeto de interesse social e acadêmico, principalmente a partir do século $X X$, com o fortalecimento dos conceitos de direitos sociais, democratização, acesso à informação e aprendizagem ao longo da vida. Poder-se-ia imaginar que chegaríamos ao séc. XXI com a universalização de tais bibliotecas, com a universalização de políticas de educação e cultura, propiciando aos cidadãos plenos direitos de acesso à informação e à cultura.

Nosso trabalho demonstra que, terminado já o primeiro decênio do séc. $X X I$, no Brasil e, especificamente em Minas Gerais, ainda estamos almejando os mesmos objetivos que outros países colocaram e cumpriram no séc. XX: a universalização das bibliotecas públicas como condição para a plena cidadania, da infância até o fim da vida. Segundo Fonseca (2007, p. 51) trata-se de um ciclo vicioso na política

[...] a explicação mais plausível para a pouca ou nenhuma atenção que as autoridades brasileiras - até mesmo os ministérios chamados da Educação e da Cultura - dispensam às nossas bibliotecas: já que delas não se beneficiaram na infância e na mocidade, como podem, depois de adultos, avaliar a importância que, no máximo, apenas platonicamente admitem?

Relatando questionamento que teria feito ao arquiteto Lúcio Costa sobre o "esquecimento" das bibliotecas públicas no projeto de Brasília, é ainda Fonseca (2007, p. 51) quem registra a resposta: "esquecera-se das bibliotecas porque nunca as vira funcionar em nosso país!". Lamentável realidade que o autor chama de "o grande escândalo 
da biblioteconomia nacional".

O presente artigo é fruto da conjugação entre uma pesquisa de mestrado com uma de iniciação científica, e teve como objetivo descrever e analisar as políticas para bibliotecas públicas de Minas Gerais, visando compreender os possíveis avanços ou retrocessos destas políticas públicas. O corte temporal vai desde a criação da Secretaria de Estado de Cultura em 1983 até 2012, quando uma das pesquisadoras passa a fazer parte da gestão do Sistema Estadual de Bibliotecas Públicas Municipais - o que poderia trazer impedimento ético na pesquisa. Aqui está presente parte desta pesquisa e de seus resultados.

\section{BIBLIOTECAS PÚBLICAS NO BRASIL E EM MINAS GERAIS}

O Dicionário de Biblioteconomia e Arquivologia traz a definição de biblioteca pública como "a que é posta à disposição da coletividade de uma região, município ou estado, e que é financiada, principalmente por dotações governamentais" (CUNHA; CAVALCANTI, 2008, p. 52) destacando, portanto, seu público de usuários e sua entidade mantenedora. De fato, essa definição concisa aponta dois elementos fundamentais de tais bibliotecas, mas seu conceito foi se desenvolvendo historicamente, acompanhando o desenvolvimento social, mas também sofrendo influências de organismos internacionais, sempre visando

[...] proporcionar recursos e serviços, numa diversidade de mídias, a fim de atender às necessidades de indivíduos e grupos em material de educação, informação e desenvolvimento pessoal, inclusive sua recreação e lazer (FEDERAÇÃO INTERNACIONAL DE ASSOCIAÇÔES DE BIBLIOTECÁRIOS E BIBLIOTECAS, 2012, p. 2).

Nas subseções seguintes apresentaremos as origens das bibliotecas públicas no mundo, no Brasil e em Minas Gerais, bem como sua inserção nas políticas públicas culturais. 


\subsection{Surgimento das Bibliotecas Públicas e seu Conceito}

Segundo Martins (2002, p. 71) as bibliotecas são instituições antigas, mais antigas que o próprio livro. Desde a Antiguidade já existiam bibliotecas, mas até a Renascença estas eram tidas como sagradas, com acesso restrito aos monges e sacerdotes, imbuídas de uma aura de mistério. No que se refere às bibliotecas públicas, uma das primeiras de que se tem referência teria sido idealizada pelo general Júlio César, tendo sido construída mesmo após sua morte, pelo orador Asínio Pólio, no ano 39.d.C. "[..] estabelecendo simbolicamente a primeira biblioteca pública do templo romano da liberdade" (MARTINS, 2002, p. 78). No entanto, importantes obras de referência se contradizem no que diz respeito a qual foi a primeira aberta ao público, e os questionamentos recaem entre a de Ulpiana, fundada por Trajano, a Ambrosiana, de Milão, fundada pelo cardeal Borromeu em 1608, a Biblioteca Marciana, de Florença, no séc. XV e a Vaticana, fundada pelo Papa Nicolau, por volta de 1450 (MARTINS, 2002, p. 78-79).

Segundo Silveira (2014), as primeiras bibliotecas públicas mantidas pelo poder público foram as inglesas, criadas para contribuir para o progresso e ordem social, após a revolução industrial. Já nos Estados Unidos, as bibliotecas públicas foram criadas pelo que Mueller (1984) denominou de movimento de auto-educação, pois a educação era considerada uma forma de cura para os problemas sociais.

Com a criação das bibliotecas públicas no período da revolução industrial, além de seus objetivos positivistas de ordem, progresso e boa leitura (SILVEIRA, 2014), as bibliotecas passam a desenvolver seu papel social, propiciando a socialização cultural na comunidade $\mathrm{e}$ atuando com a missão de preservação do conhecimento, mas também desempenhando o papel educacional.

No Brasil, considera-se a primeira biblioteca aberta ao público a Biblioteca Nacional. Sua origem data do ano de 1807, quando a Corte portuguesa foge para o Rio de Janeiro, trazendo a Real Biblioteca. Porém, somente em 1824 ela foi aberta ao público. Entretanto, apesar 
de se constituir como uma biblioteca de acesso público, esta biblioteca não se configurou efetivamente como instituição de livre acesso, como corrobora Suaiden (2000, p. 52) quando diz que "a vinda da Biblioteca e da Imprensa Real também não representou indicadores efetivos do acesso e da disponibilidade de informação para toda a sociedade". Segundo Cesarino (2007) "[...] em 1811 é criada em Salvador a primeira instituição com o nome de biblioteca pública", o que também demonstrado pela citação de Suaiden (2000, p. 52),

No entanto, no dia 5 de fevereiro de 1811, Pedro Gomes Ferrão de Castello Branco encaminhou um projeto ao governador da Capitania da Bahia, solicitando a aprovação do plano para a fundação da Biblioteca. Esse documento, que historicamente é o primeiro projeto na história do Brasil com o objetivo de facilitar 0 acesso ao livro, mostrava grande preocupação com a área da educação. O plano foi aprovado, e a Biblioteca inaugurada no Colégio dos Jesuítas em 4 de agosto de 1811. Posteriormente, todas as providências para a fundação de bibliotecas partiram sempre da iniciativa governamental (SUAIDEN, 2000, p. 52).

Durante muitos anos o Manifesto de Caracas (e mesmo anterior a ele, os Manifestos da UNESCO de 1949 e 1972) orientou a atuação das bibliotecas públicas. Em 1994 a UNESCO juntamente com a IFLA lançou novamente $O$ Manifesto para as Bibliotecas Públicas, que tem servido de parâmetro para pensar o conceito das bibliotecas públicas, seu papel social e sua missão. Este manifesto destacou 12 missões para as bibliotecas públicas, dos quais foram selecionadas algumas para serem discutidas:

- Criar e fortalecer hábitos de leitura nas crianças desde a mais tenra idade;

- Apoiar tanto a educação individual e autodidata como a educação formal em todos os níveis;

- Promover o conhecimento da herança cultural, apreciação das artes, realizações e inovações científicas;

- Garantir acesso aos cidadãos a todo tipo de informação comunitária; 
- Proporcionar serviços de informação adequados a empresas locais, associações e grupos de interesse;

- Facilitar o desenvolvimento da informação e da habilidade no uso do computador (UNESCO, 1994).

Nos tópicos destacados acima se percebe o papel da biblioteca pública como incentivadora da leitura, indicando a importância do desenvolvimento de ações neste sentido. $O$ apoio à educação também foi destacado, tema este muito discutido, uma vez que as bibliotecas, durante longo período, voltaram-se para as pesquisas escolares unicamente, esquecendo-se do seu papel cultural. Essa situação pode ter sido impulsionada pela precariedade e pela falta das bibliotecas escolares. Atualmente valoriza-se nas bibliotecas públicas a ideia de educação ao longo da vida, para os que já saíram da escola regular.

Para que a biblioteca pública possa desempenhar o papel de promoção do acesso à informação, da cidadania, de conhecimento de si e do outro e ser um equipamento cultural aberto às diversas manifestações culturais humanas é primordial que os governos invistam recursos e formulem políticas públicas que garantam esses recursos. A biblioteca pública não é um organismo independente pois, além de depender de uma série de fatores presentes em seu ambiente, ela é vinculada ao poder público, seja ele municipal, estadual ou federal, e demandará políticas específicas para sua conceituação, atuação e manutenção. O papel primordial das bibliotecas públicas na vida das pessoas foi discutido por Castrillón (2011):

Bibliotecas que ofereçam um acesso real e universal à informação, sem a qual não é possível sobreviver em mínimas condições de humanidade. Muitas vidas poderiam ser salvas e muitos seres humanos viveriam de maneira mais digna se o acesso à informação fosse realmente universal (CASTRILLÓN, 2011, p. 37).

Pensar nas funções informacional, educativa, cultural e de fruição da biblioteca pública requer reflexão constante e comprometida de todos 
os atores envolvidos, tanto na prática quanto na teoria. Só assim será possível avançar em suas políticas públicas.

2.2 Minas Gerais: A Secretaria de Estado da Cultura, a Superintendência de Bibliotecas Públicas de Minas Gerais e a Biblioteca Pública Estadual Luiz de Bessa

Antes mesmo da institucionalização da Secretaria de Estado da Cultura e da Superintendência de Bibliotecas Públicas de Minas Gerais (SUB-MG) ${ }^{1}$, foi criada a Biblioteca Pública Estadual Luiz de Bessa (BPELB). Instituída em 1954, por meio da Lei o 1087 de 2 de junho (MINAS GERAIS, 1954), pelo então governador Juscelino Kubtschek, a BPELB teve seu prédio projetado pelo arquiteto Oscar Niemeyer, sendo inaugurada em 1961, passando a integrar o conjunto arquitetônico da Praça da Liberdade. A curadoria de seu acervo ficou a cargo de uma comissão presidida por Eduardo Frieiro, da qual participavam os bibliotecários Hélio Gravatá, Etelvina Lima e Cacilda Basílio de Souza Reis. Dos seis andares projetados por Oscar Niemeyer, apenas três foram construídos, devido a cortes drásticos no orçamento. $O$ término da obra foi possível pelo trabalho de detentos da Casa de Correção, por determinação do Governador José Francisco Bias Fortes (CESARINO, 2006, p. 24).

Em mensagem enviada à Assembleia de MG, Juscelino afirmava que,

[...] a finalidade da biblioteca moderna não se limita a completar os estudos secundários e universitários, ou a proporcionar ao trabalhador intelectual as obras e documentos de que precisa. Tem ao mesmo tempo, uma função cultural altamente democrática (KUBITSCHEK, 1954 apud CESARINO, 2006, p. 22).

1 Que em janeiro de 2014 passou a coordenar também as ações do Suplemento Literário, denominando-se Superintendência de Bibliotecas Públicas e Suplemento Literário (SUBSL). 
O pronunciamento do governador destacava a função cultural e de participação social da biblioteca pública, na qual a BPELB se inseria, e a partir de então deveria empreender esforços para se desenvolver com os recursos que lhe seriam destinados.

Com o passar dos anos, seu acervo e serviços foram ampliando, o que demandou a expansão de seu espaço físico. No final da década de 1990, o Governo do Estado destinou um prédio da Rua da Bahia, que se encontrava fechado, para ser o anexo da Biblioteca Pública Estadual Luiz de Bessa, sendo denominado Anexo Professor Francisco Iglésias.

A BPELB, seguindo a concepção de JK, chegou ao século XXI como um equipamento cultural dinâmico, vivo, guardando e disseminando informação, recebendo e agregando várias manifestações culturais. Atualmente atende a um público de cerca de 400 mil pessoas por ano e guarda um acervo de cerca de 520 mil itens, tornando-se referência para as mais 800 bibliotecas municipais do estado de Minas Gerais (CESARINO, 2014), além de fazer parte do Circuito Cultural Praça da Liberdade, um programa estruturador do Governo de Minas nesta primeira década do séc. XXI.

A BPELB conta com dois prédios e diversos serviços e setores, a saber: o Setor de Empréstimo Domiciliar, com acervo de diversas áreas do conhecimento, com ênfase para a literatura; o Setor de Referência e Estudos, que possui obras de referência e para consulta; o de Periódicos, com assinatura de jornais e revistas nacionais e internacionais; o Setor Infantojuvenil, que tem seu acervo selecionado e dinamizado de forma particular para o público a que se destina; o Setor Braille, referência nacional em acessibilidade, possui acervo e serviços especializados para pessoas com deficiência visual; as Coleções Especiais, que abarcam as coleções particulares, especiais, as obras raras; a Coleção Mineiriana, que guarda a produção bibliográfica de autores mineiros e sobre Minas Gerais, entre outras; a Hemeroteca Histórica, setor responsável por preservar os jornais e revistas históricos e raros, especialmente os editados em Minas Gerais. Todos os setores 
da Biblioteca possuem seus acervos informatizados, utilizando o software Pergamun, que pode ser consultado pela internet ${ }^{2}$.

Para além dos setores, existem outros espaços que auxiliam a conceituação da Biblioteca como um centro cultural: o Teatro José Aparecido de Oliveira, o Teatro de Arena e as galerias Paulo Campos Guimarães e Passarela Cultural, que recebem, por meio de edital, exposições artísticas e literárias anualmente.

Para ampliar o acesso, a BPELB conta com atividades de extensão bibliotecária, que extrapola o limite geográfico de atuação da biblioteca e leva para comunidades distantes e outras instituições a oportunidade de interagir com a produção literária e com as atividades que dela derivam, e são elas: o Carro-Biblioteca, que atende a 6 bairros da região metropolitana de Belo Horizonte, e o serviço de Caixa-Estante, que hoje está disseminada em 17 instituições públicas e não governamentais.

No sentido de incentivar a leitura, a BPELB desenvolve inúmeros projetos, entre eles a Hora do Conto e da Leitura, os projetos Aula na Biblioteca e Em Destaque, o ciclo de palestras Encontros com a Leitura, a Hora do Conto e da Leitura Braille e muitos outros.

Todas as informações referentes à Biblioteca Pública Estadual Luiz de Bessa, desde sua criação em 1954 até os dias atuais, são importantes para introduzir o tema da criação da Secretaria de Estado de Cultura, do Sistema Estadual de Bibliotecas Públicas e da Superintendência de Bibliotecas Públicas.

A Secretaria de Estado da Cultura,

[...] foi criada em 1983 por meio da Lei 8.502 de 19 de dezembro, órgão até então denominado Coordenadoria de Cultura, vinculado à Secretaria de Estado do Governo. O Artigo $7^{\circ}$ do Capítulo II esclarece que sua competência é [...] propor a política da Cultura e planejar, coordenar, executar e controlar as atividades

2 Informações: www.cultura.mg.gov.br. 
governamentais relativas ao desenvolvimento cultural e artístico e à preservação do patrimônio histórico e artístico do Estado [...] (MINAS GERAIS, 1983).

Somente em 1994 é que a Superintendência de Bibliotecas - SUB foi institucionalizada pela Lei 11.714, de 26/12/1994 (MINAS GERAIS, 1994a) e suas ações e objetivos regulamentados pela Lei 11.726 de 30/12/1994 (MINAS GERAIS, 1994b). A partir deste momento a SUB passou a coordenar as ações da BPELB e das bibliotecas públicas municipais.

Em 2008 eram 780 bibliotecas públicas municipais, em 736 municípios (CESARINO, 2008), formando o Sistema Estadual de Bibliotecas Públicas Municipais (SEBPM), cuja coordenação tem o propósito de ampliar e modernizar a rede de bibliotecas públicas de Minas Gerais. O SEBPM oferece assessorias para as bibliotecas municipais, visitas técnicas e de fiscalização, promove cursos de capacitação e desenvolve as Exposições Literárias Itinerantes, como uma ação de incentivo à leitura para a capital e para os demais municípios.

A SUB e o Sistema Estadual de Bibliotecas Públicas Municipais têm como principal desafio atuar em um estado de vastas dimensões, com diferenças cultuais e econômicas muito marcadas e grande número de municípios. A maioria dos municípios tem como característica o pouco investimento em suas bibliotecas, desde a contratação de pessoal, passando pela compra de acervo e desenvolvimento de ações de mediação e incentivo à leitura. Muitas bibliotecas continuam submetidas à vontade política de seus dirigentes, que desconhecem o valor da leitura, e julgam a biblioteca como apenas uma fonte de gasto e preocupação. Esta situação é fruto da falta de criação e execução de políticas públicas pensadas pelo poder público com a participação da comunidade, o que reforça o cenário de descaso na maioria dos municípios mineiros.

Conhecer o que já foi realizado no Estado de Minas Gerais para as bibliotecas públicas e analisar os possíveis avanços ou retrocessos 
após as políticas implementadas desde a criação da Secretaria de Estado de Cultura e do Sistema Estadual de Bibliotecas Públicas, pode auxiliar na criação de novos modelos.

\subsection{Políticas Públicas}

A área das políticas públicas, que nasceu como subárea das Ciências Políticas, tem recebido olhares mais interessados, como campo de estudo e atuação, nas últimas décadas. Os Estados Unidos, após a Europa, começaram o movimento de pesquisar a disciplina de Políticas Públicas, como analisa Souza (2006).

Por ser um campo complexo, de cuja formulação, gerenciamento e avaliação vários atores participam, sendo consideradas um conjunto de ações e não uma ação isolada, as políticas públicas possuem como característica marcante a interdisciplinaridade, que abrange vários modelos, sistemas e teorias. Do ponto de vista teórico-conceitual, as políticas são construídas da interação das disciplinas do campo da sociologia, da ciência política e da economia. Outras disciplinas também partilham interesses comuns e contribuem para área, como a antropologia, geografia e gestão.

Souza (2006) conceitua política pública como,

[...] o campo do conhecimento que busca, ao mesmo tempo, "colocar o governo em ação" e/ou analisar essa ação (variável independente) e, quando necessário, propor mudanças no rumo ou curso dessas ações (variável dependente). A formulação de políticas públicas constitui-se no estágio em que os governos democráticos traduzem seus propósitos e plataformas eleitorais em programas e ações que produzirão resultados ou mudanças no mundo real (SOUZA, 2006, p. 26).

A elaboração de políticas públicas passa por alguns estágios, nem sempre lineares e obrigatórios, dentro de um ciclo. Grande parte dos teóricos da área define algumas etapas deste processo, a saber: 
agenda; elaboração; implementação; execução; acompanhamento e avaliação (SARAIVA, 2006, p. 33).

Uma importante constatação deve ser feita a respeito das políticas estaduais. Desde a Constituição Brasileira de 1988, fica estabelecida no Brasil, uma forma muito peculiar de federalismo, conforme apresenta Abrúcio (2010, p. 44):

O principal mote do novo federalismo inaugurado pela Constituição de 1988 foi a descentralização. Processo que significava não só passar mais recursos e poder aos governos subnacionais, mas, principalmente, tinha como palavra de ordem a municipalização. Nessa linha, o Brasil se tornou uma das pouquíssimas federações do mundo a dar status de ente federativo aos municípios.

Nesse formato federativo os municípios têm o status de ente da federação, com autonomia. Assim, os municípios não se submetem administrativamente aos governos estaduais.

Após esta breve discussão sobre a origem e conceitos sobre as políticas públicas, aprofundaremos nas questões pertinentes à área da cultura e mais especificamente às bibliotecas públicas.

\subsubsection{Políticas Públicas Culturais}

A política cultural é uma política pública setorial, assim como as da educação, saúde ou previdência social, e enfrenta problemas como todas as outras. Alguns problemas são advindos especialmente da fragmentação e descontinuidade da intervenção estatal, além dos parcos recursos.

As políticas públicas para a área para cultura são especialmente complexas, na medida em que a cultura ocupa-se com o intangível, com o subjetivo e muitas vezes, com manifestações não documentadas, além de ter papel preponderante na construção social do país.

O antropólogo e pesquisador Frederico A. Barbosa da Silva, do Instituto de Pesquisa Econômica Aplicada (Ipea), em um estudo 
minucioso sobre as políticas culturais do Ministério da Cultura salientou a profundidade deste tipo de política:

As políticas culturais estão ancoradas nos direitos e na ideia de universalidade do acesso aos bens culturais, simbólicos e materiais. A democratização e o acesso à cultura são valores de amplo acolhimento entre os diferentes atores sociais. De maneira geral, os objetivos gerais que guiam outras políticas sociais se aplicam às políticas culturais, que também são consideradas como meios para enriquecer a existência das pessoas e criar igualdade social. No entanto, as instituições culturais encontram-se diante de fortes restrições que limitam sua abrangência e acesso (SILVA, 2007, p. 11).

Ao pensar as bibliotecas públicas, é bastante comum vinculá-las à Educação, tendo em vista seu histórico de apoio à formação escolar. No entanto as bibliotecas públicas estão inseridas na política cultural, como explica Machado (2010):

A sociedade em geral costuma relacionar as bibliotecas públicas à área de Educação. No entanto, elas estão inseridas institucionalmente na área de Cultura. Portanto, são as políticas culturais que, por meio de sua administração pública e do conjunto de leis e regulamentações, buscam caminhos para 0 fortalecimento dessas bibliotecas e o estabelecimento de ações de longo alcance, com caráter permanente (MACHADO, 2010, p. 97).

Um levantamento histórico das políticas públicas para o livro, leitura e bibliotecas públicas no âmbito federal foi sistematizado por Paiva (2008), e especificamente para as bibliotecas por Machado (2010).

No entanto, é importante salientar que, para a construção de políticas que reflitam a realidade e diversidade da sociedade, e também que não se configurem em meras cópias do que já foi realizado, é importante que essas políticas sejam conhecidas e sistematizadas, com o intuito de subsidiar novas ações que proporcionem efetivo avanço. Machado (2010) defende esta posição ao dizer que, 
[...] é importante lembrar que o Brasil sempre teve uma grande dificuldade em coletar, organizar e sistematizar informações sobre suas ações, acervos e equipamentos culturais. Esse fato é apontado pela UNESCO (2006) em seu texto sobre as estratégias de atuação no Brasil, onde afirma que pouco se fez para avaliar o verdadeiro valor da cultura no país. [...] Afinal, como construir políticas públicas de qualidade se não temos um diagnóstico da nossa realidade? (MACHADO, 2010, p. 95).

É preciso que as políticas públicas para a área de bibliotecas, livro e leitura sejam políticas de estado, para além das políticas de governo, que dominam o contexto político há tanto tempo. Do nosso ponto de vista, a diferença primordial entre uma política de estado e uma política de governo está relacionada à continuidade. As políticas de governo são pensadas e implementadas de acordo com o perfil e a proposta de uma gestão. Diferente das políticas de estado, que devem ser implantadas ao longo do tempo, ainda que passando por diferentes governos. Este assunto foi discutido por Rua e Romanini, que discorreram sobre a diferença entre uma política de estado e uma política do governo.

[...] as Políticas de Estado tratariam de policies mais permanentes do que aquilo que se restringe ao período no qual um governo exerce o poder (normalmente, de quatro a oito anos em países presidencialistas). Seriam mais duradouras e consolidadas. Além disso, implicariam articulações entre as diferentes áreas setoriais de políticas públicas com o intento de que toas elas convergissem para os objetivos do Estado. Em contraposição, as Políticas de Governo seriam passageiras, vigorariam somente durante o mandato de seus formuladores, e não necessariamente se concentrariam em torno de finalidades comuns, porquanto os governos distribuem as áreas de atuação setorial consoante critérios políticos, que podem levar à convergência ou à dispersão das policies (RUA; ROMANINI, 2013, p. 1).

A biblioteca pública funciona como veículo para o acesso público à informação, este último um dos campos de estudo da Ciência da Informação. Este é um tema de debate na era da Sociedade da 
Informação, e as bibliotecas públicas devem ser pensadas e estudadas como meio para proporcionar a possibilidade de acesso e uso da informação de forma crítica, autônoma e consciente.

Sendo assim, pesquisar as bibliotecas públicas dentro do contexto das políticas públicas poderá servir como um suporte importante para que os gestores públicos programem novas ações, contribuindo para o estudo do papel social da informação e das políticas culturais no campo da Ciência da Informação.

\subsubsection{Instrumentos de Gestão do Estado de Minas Gerais}

O Estado de Minas Gerais utiliza para o planejamento e monitoramento de suas políticas públicas alguns instrumentos, que norteiam suas ações. A compreensão destas informações torna-se útil na medida em que facilita a participação popular na elaboração das políticas públicas e aprimora seu acompanhamento.

Nestas primeiras décadas do século XXI, a estratégia de Governo, ou seja, o planejamento governamental de desenvolvimento em longo prazo se dá por meio do Plano Mineiro de Desenvolvimento Integrado (PMDI), que foi criado em 2003, como nos esclarece as informações constantes no site da Assembleia Legislativa:

Em Minas Gerais, o PMDI foi pensado para ser colocado em prática seguindo uma premissa participativa, baseada na interlocução entre governo e sociedade civil, seja por meio das suas mais diversas entidades representativas, seja por meio da oferta de mais canais para a população se manifestar. Ouvir para governar é um princípio não apenas democrático, mas que pode ser aplicado de forma muito eficiente à gestão pública (MINAS GERAIS, 2015b).

Após seu lançamento em 2003 houve uma revisão em 2007. Em 2011 o PMDI passou por nova revisão, resultando no planejamento 2011-2030, em vigor até o presente, que foi estruturado por meio de 11 Redes de Desenvolvimento Integrado. Perpassando por diversas áreas de interesse social, esta revisão trouxe a inclusão da área da cultura, 
integrante da Rede de Identidade Mineira, que englobava a cultura, o esporte e o turismo.

Outro instrumento representativo do planejamento $\mathrm{e}$ monitoramento das políticas públicas do Estado de Minas Gerais é o Plano Plurianual de Ação Governamental (PPAG). Este é um instrumento de médio prazo e tem como norte um horizonte de quatro anos. Constam neste planejamento todas as ações, programas e projetos das atividades meio e finalísticas, que devem ser elaboradas em consonância com o PMDI.

É o PPAG que dá visibilidade às políticas que o governo se compromete a implantar, com vigência iniciada no segundo ano de mandato de um governo e término no primeiro ano de mandato do seguinte, estabelecendo metas e estratégias gerenciais e de alocação de recursos. Como instrumento de planejamento das atividades da administração pública, - PPAG visa a orientar a execução do orçamento público, alocando os recursos disponíveis preponderantemente nos programas e ações que contribuem para a consecução dos objetivos estratégicos delineados no PMDI (MINAS GERAIS, 2015a).

As especificações dos recursos financeiros destinados para cada ação e suas despesas são realizadas anualmente pela Lei Orçamentária Anual (LOA), que é outro instrumento de gestão do Estado.

É a LOA que expressa a política econômico-financeira e o programa de trabalho governamental, especificando os recursos que financiarão cada ação do PPAG. Nela estão os orçamentos fiscal (de todos os Poderes e órgãos da administração pública), da seguridade e de investimento das empresas estatais (MINAS GERAIS, 2015a).

Já o Acordo de Resultados é um "instrumento de pactuação de resultados utilizado pelo Governo do Estado de Minas Gerais, nos moldes do contrato de gestão" (LEMOS, 2009, p. 2). O contrato de gestão insere-se no conceito de Gestão para Resultados, que é: 
[...] a gestão baseada na elaboração de indicadores a serem acompanhados e avaliados periodicamente objetivando a verificação do efetivo alcance dos resultados pré-fixados. Visa facilitar para as instituições públicas a direção efetiva e integrada do processo de criação de valor público, a consecução dos objetivos de governo e a melhora contínua das instituições (LEMOS, 2009, p. 3).

Entre os objetivos do Acordo de Resultados estão: a definição de prioridades, que são representadas por indicadores e metas com vistas para os resultados; a melhoria da qualidade e eficiência dos serviços prestados à sociedade; o planejamento estratégico das ações do governo; a transparência das ações das instituições públicas, facilitando o controle social e a implementação de uma cultura voltada para resultados, estimulando e valorizando servidores, dirigentes e órgãos para que atinjam seus resultados.

Como se pode observar, a inclusão de algum tema para inserção nas políticas públicas do Estado de Minas Gerais depende de um planejamento de longo prazo e da disponibilidade em incluir também nos orçamentos, os recursos para execução dos projetos.

\section{METODOLOGIA}

Esta foi uma pesquisa qualitativa concretizada por meio da análise do conteúdo dos atos legais e documentos administrativos, sob o viés da análise documental, das políticas relacionadas a bibliotecas públicas em Minas Gerais, entre 1983 e 2012. Segundo Bardin (2011, p. 47), a análise documental é uma "operação ou um conjunto de operações visando representar o conteúdo de um documento sob uma forma diferente do original, a fim de facilitar, num estado ulterior, a sua consulta e referenciação".

A pesquisa foi desenvolvida seguindo alguns passos, que foram se mostrando mais claros na medida em que a mesma foi se desenvolvendo. A primeira fase foi realizada com o levantamento histórico e leitura técnica das políticas públicas de Minas Gerais, no período. As Leis, Decretos e Resoluções foram pesquisados no site da Assembleia Legislativa (MINAS GERAIS, 2015a), que disponibiliza todo 
o conteúdo on-line e atualizado. Ainda na primeira fase foram analisados os documentos administrativos da SUB do período de 1983 a 2012, totalizando 837 metros lineares.

O último passo da primeira fase foi o levantamento dos dados do Recadastramento das bibliotecas públicas municipais, realizado pelo Sistema Estadual de Bibliotecas Públicas Municipais, dos anos de 2007, 2009 e 2011.

A segunda fase contou com a análise documental propriamente dita dos registros, ou seja, a leitura, descrição e caracterização de todo material sobre políticas governamentais para as bibliotecas públicas em Minas Gerais no período. Nesta fase foi realizada a análise de conteúdo dos dados, ou seja, a descrição dos documentos em lista cronológica, registros sobre a natureza, fonte e breve apanhado de seu conteúdo.

Durante a segunda fase da pesquisa foram realizadas as entrevistas semiestruturadas com os Superintendentes de Bibliotecas Públicas no período entre 1983 a 2012 (CESARINO, 2007, p. 25). Os entrevistados foram escolhidos considerando ser 0 cargo de Superintendente o de gestor máximo da instituição e por isso, tendo participado da elaboração e execução das políticas públicas da área.

A terceira fase da pesquisa foi se delineando à medida que os dados eram analisados. Optou-se por dividir o período pelos mandatos dos governadores, apontando os secretários de cultura de cada governo e também os superintendentes de bibliotecas. Isso é particularmente necessário nas políticas brasileiras por causa da descontinuidade das políticas entre um governo e os subsequentes. O conjunto de dados documentais e entrevistas delinearam o quadro mais próximo do real para o período recortado pela pesquisa, para além da letra fria dos atos legais. Após a análise pormenorizada dos dados por mandatos (que não é apresentada neste artigo), foram finalmente elaboradas categorias de análise, a seguir apresentadas. 


\section{ANÁLISE CATEGORIZADA E DISCUSSÃO}

A biblioteca pública é um local privilegiado de acesso à cultura e à informação nas comunidades em que se insere, trabalhando para disseminar a informação, preservar o patrimônio bibliográfico e desenvolver ações para formação de leitores. Atende a todos os públicos, desde o bebê, a criança, o jovem, até os adultos e idosos. Todas as pessoas, de qualquer raça, classe social, credo ou afinidade política têm espaço em uma biblioteca pública. Para suprir toda a necessidade informacional, este equipamento deve ter um acervo diversificado, atualizado, voltado para o público que a frequenta, mas deve também, na medida do possível, proporcionar novas experiências literárias, a que em outras circunstâncias esta população não teria acesso ou não demandaria. Para além de um local de acesso à informação de todos os tipos e em vários suportes, a biblioteca pública tem também a importante missão de guardar a produção bibliográfica da cidade e região na qual está inserida, concebendo-a como um lugar de memória local. A partir dessa concepção complexa é necessária a criação, implantação, manutenção e avaliação de políticas efetivas para as bibliotecas públicas, ou seja, políticas criadas considerando a variedade cultural, econômica e simbólica de cada região.

Ao longo da pesquisa foram identificados vários programas, projetos e ações voltadas para as bibliotecas públicas de Minas Gerais, sejam elas para a biblioteca estadual ou para a rede de bibliotecas municipais. Algumas categorias de análise serão discutidas a seguir:

\subsection{Marcos Legais}

Um dos marcos legais mais importantes do período pesquisado foi a institucionalização e manutenção do Sistema Estadual de Bibliotecas Públicas e posteriormente da Superintendência de Bibliotecas Públicas, dentro da Secretaria de Estado de Cultura de Minas Gerais. Apesar das mudanças de diretoria e da descontinuidade dos programas e projetos, estes organismos continuaram suas 
atividades ao longo destes quase 30 anos pesquisados, ainda que com mais ou menos recursos financeiros e logísticos. Apesar de tudo, sua constância foi bastante benéfica para que as bibliotecas não caíssem no esquecimento. No entanto, as mudanças na esfera federal sempre impactaram diretamente as ações estaduais, demonstrando a grande dependência dessas últimas.

Apesar da institucionalização do Sistema ter sido importante para as políticas públicas, este foi um dos poucos marcos regulamentados por instrumentos legais. Com exceção da Política Estadual do Livro, de 2009, nenhum outro programa ou projeto foi regulamentado, o que fragiliza sua execução e permanência.

\subsection{Rede de Bibliotecas}

A criação da rede de bibliotecas pólo foi instituída, foi extinta e continuou sendo o projeto de todos os gestores do período estudado. Foi criada em 1986 com recursos do Governo Federal, mas tão logo estes recursos deixaram de ser enviados, a rede não conseguiu prosseguir. O projeto foi repensado várias vezes, mas sempre na dependência de recursos federais ou de parcerias com empresas privadas. Seu ideário previa a modernização das bibliotecas, que seriam pólos disseminadores da política, por meio de doação de livros, equipamentos e capacitação.

Criar a rede de bibliotecas pólo é imprescindível para a interiorização e democratização da ação bibliotecária no estado. No entanto, sua implementação deve partir de um planejamento cuidadoso, considerando as diferenças regionais, a infraestrutura das prefeituras e o grau de apoio das mesmas, além de coordenação e recursos permanentes. Portanto, deve contar com recursos orçamentários da própria Secretaria, planejados a longo prazo, nessa situação incluídos no PMDI e PPAG, para não ficar à mercê de interesses empresariais ou à espera de que o governo federal resolva um problema que compete 
tão somente ao estado. Neste caso, assim como em todos os outros, deve-se pensar na permanência e continuidade do projeto.

\subsection{Relação Estado-União}

Ao longo de toda a pesquisa foi possível notar os inúmeros projetos executados pelo Sistema Estadual de Bibliotecas Públicas e Superintendência de Bibliotecas Públicas. No entanto, percebemos que a maioria dos projetos foram elaborados pela esfera federal, seja 0 Instituto Nacional do Livro (INL), Sistema Nacional de Bibliotecas Públicas (SNBP) ou Fundação Biblioteca Nacional (FBN). Destacou-se especialmente o início da década de 1980 , com os projetos do INL. A própria criação do Sistema Estadual de Bibliotecas Públicas foi viabilizada por repasse de recursos federais. Quando não era um programa federal, era algum projeto patrocinado por alguma empresa, com interesses claramente mercadológicos. $O$ fato é que o Estado atuou muito mais como articulador e executor dos programas e projetos, do que como proponente. O projeto Construindo uma Minas Leitora, quando Projeto Estruturador, foi uma das poucas exceções.

Esses projetos tiveram, em sua maioria, um perfil bastante semelhante: baseavam-se na doação de kits de livros, equipamentos e vez por outra contemplaram a capacitação do pessoal que atuava nas bibliotecas municipais. Para agravar a situação, alguns projetos contavam, exclusivamente, com doações da comunidade e empresas.

\subsection{Relação Estado-Municípios}

Outra questão que se fez presente foi a fragilidade da relação entre os municípios e o Estado. Com a federalização dos municípios ocorrida em 1988, tema já discutido no referencial teórico, o Estado não pode intervir diretamente nas ações municipais. Sendo assim, a cada mudança de gestão ocorrida pelas eleições, inicia-se novamente todo o trabalho de sensibilização e convencimento dos gestores públicos sobre a importância das bibliotecas e de seu investimento e apoio. Uma das 
consequências mais graves desta situação é a inconstância das bibliotecas, pois uma biblioteca que desenvolve um trabalho de excelência hoje, pode amanhã estar fechada, simplesmente por interesse e vontade política, e não por demanda da comunidade.

\subsection{Papel do Bibliotecário}

A realização de um concurso para o cargo de Bibliotecário, no ano de 2006, para a Superintendência de Bibliotecas, impactou positivamente nas ações da instituição. Sendo assim, cabe aqui ressaltar a importância de se pensar no papel do profissional bibliotecário, não só como executor da política pública, mas como aquele que pensa, planeja, elabora, acompanha e avalia as políticas públicas de sua área. Ao longo da história da SUB o papel gestor dos bibliotecários foi preponderante para a elaboração e continuidade das atividades.

\subsection{Capacitação e Eventos}

Como comentado por Paiva (2008, p. 112), a grande maioria dos programas federais, e neste caso também os estaduais, voltam suas ações para as bibliotecas por meio do envio de livros e equipamentos. Em Minas Gerais, a realidade não é diferente, no entanto, notou-se grande esforço em aliar o envio destes materiais à capacitação do pessoal que trabalha nas bibliotecas. Os cursos de capacitação, encontros regionais, estágios na biblioteca estadual e encontros estaduais que ocorreram ao longo de todo o período pesquisado demonstram a preocupação dos gestores em formar e capacitar quem fará a mediação do acervo com o público.

Os cursos de capacitação contribuem muito para a atuação dos gestores, pois a grande maioria não possui formação específica para atuar em bibliotecas públicas e o mero envio de livros não significa potencializar o uso do acervo nem formar leitores. Já os eventos atuam muito mais como articuladores, na medida em que aproximam as 
autoridades municipais dos gestores estaduais e federais. No entanto, é importante ressaltar que a falta de recursos para subsidiar a viagem dificulta a participação nos cursos oferecidos.

\subsection{Comunicação com os Municípios}

Um aspecto constante identificado na pesquisa foi a dificuldade de comunicação da Superintendência de Bibliotecas e Sistema Estadual de Bibliotecas Públicas Municipais com os municípios. Seja para a divulgação de um projeto ou evento, seja para o cadastro das bibliotecas municipais, durante os quase 30 anos pesquisados esta questão se colocou muito presente. Um cadastro atualizado não servirá somente para obter os contatos com os municípios, ele servirá, principalmente, para se conhecer a realidade de cada biblioteca, desde seu acervo e infraestrutura, passando pelos recursos humanos, até as ações desenvolvidas e formas de financiamento. Recursos informacionais, na forma de cadastro atualizado das secretarias e das bibliotecas públicas municipais, são condição básica para se pensar e planejar políticas públicas para um Estado com grandes dimensões geográficas.

\subsection{Financiamento}

Percebemos que a destinação de recursos para as bibliotecas mineiras sempre foi um problema. Para suprir esta falta, a SUB recorreu ao financiamento de seus programas e projetos por meio de Leis de Incentivo, o que foi recorrente no período pesquisado, especialmente no início deste século. Muitos avanços foram proporcionados à BPELB e ao Sistema Estadual de Bibliotecas Públicas, no entanto, nota-se a fragilidade das ações da cultura, uma vez que seus gestores precisam valer-se de outras formas de financiamento que não os recursos do tesouro. Desta maneira, causa-se grande instabilidade e descontinuidade nas ações implantadas ou, em muitos casos, impossibilidade na medida em que a não captação dos projetos simplesmente inviabiliza sua execução. A captação ou não de um 
projeto fica a cargo dos interesses mercadológicos das empresas incentivadoras, já que não podem contar todo o tempo com pessoal próprio para os trâmites burocráticos necessários antes, durante e depois de se conseguir aprovar um projeto.

Mesmo quando há recurso orçamentário para realizar os projetos, este entrave se coloca: a burocracia. Desde o início do período pesquisado até os anos mais recentes, vimos a dificuldade para repassar o dinheiro para as prefeituras, ou mesmo para executar os projetos. A burocracia dos processos é própria do setor público, mas o fato é que pode dificultar ou impedir que um serviço ou produto ou serviço chegue ao cidadão.

É obrigação do poder público investir recursos consistentes e persistentes para que, em longo prazo, a bibliotecas públicas possam desempenhar, efetivamente, seu papel nobre, mas também desafiador, na sociedade.

\subsection{Políticas de Estado ou Políticas de Governo}

O grande número de projetos demonstra a descontinuidade das políticas públicas mineiras para a área de bibliotecas. $O$ projeto de maior duração talvez seja o Construindo uma Minas Leitora, que durou o período dos mandatos de dois governadores. Possivelmente sua permanência deveu-se ao fato da continuidade partidária. No entanto, mesmo de longa duração, o projeto se configura uma política de Governo. Outro projeto que esteve presente durante todo o período pesquisado foi o de criação da rede de bibliotecas pólo. Neste caso, poderíamos considerá-lo uma política de Estado, na medida em que está regulamentado por Lei. Entretanto, nunca recebeu recursos representativos e exclusivos para sua efetiva implementação e continuidade. Em Minas Gerais, para a construção de uma política de Estado na área das bibliotecas públicas, é necessário que o tema esteja incluído nos já citados Plano Mineiro de Desenvolvimento Integrado e 
Planejamento Plurianual, que são os instrumentos de planejamento adotados.

\subsection{O Plano Estadual do Livro e Leitura}

Como mencionado anteriormente, o Plano Nacional do Livro e Leitura (PNLL) indica a formulação de planos estaduais e municipais, nos mesmos moldes de ação continuada e sistemática. Por se tratar de um planejamento de médio e longo prazos, com metas e objetivos integrados, é possível que a questão da continuidade e financiamento das políticas públicas para a área estejam garantidas.

A implementação do Plano Estadual do Livro e Leitura (PELL) irá avançar as políticas públicas de Minas Gerais para a área de bibliotecas, livro e leitura, por se configurar como uma política de Estado, mas é preciso cautela e planejamento para a condução do processo. Partindo do princípio de que a participação popular é um de seus pilares mais significativos, construir um plano em um estado de grandes dimensões territoriais, enorme número de municípios e diferenças culturais marcantes, é um enorme desafio e corre-se o risco de sua elaboração ficar restrita à participantes da capital, seja por falta de recursos orçamentários para deslocamento, logística dificultada pelas distâncias, ou por comodidade e interesses políticos.

Outro grande passo que poderá ser dado com a elaboração do PELL é a articulação entre a Secretaria de Estado de Cultura e a de Educação. Algumas iniciativas de projetos foram encontradas nos documentos, mas é quase nula esta parceria, o que é um espanto, considerando que ambas têm a informação, as bibliotecas e a leitura como objetos de interesse.

\section{CONSIDERAÇÕES FINAIS}

Como podemos observar nas discussões dos dados desta pesquisa, a implementação de políticas públicas para as bibliotecas públicas requer a confluência de diversos fatores. Inicia-se com a 
inclusão do tema na agenda de discussão, inserção no planejamento de médio e longo prazo, destinação de recursos financeiros e humanos para sua execução e vontade política para sua articulação. A boa vontade e esforço das equipes de servidores não serão suficientes para que o Estado consiga, efetivamente, zerar o número de município sem bibliotecas e garantir bom desempenho das mesmas.

Podemos dizer que as políticas públicas para as bibliotecas públicas têm avançado nos últimos anos, haja vista o grande número de ações documentadas ao longo deste estudo; no entanto, avançam timidamente.

Ficou claro que este é um tema amplo e complexo, que poderá ser fruto de pesquisas futuras voltadas, por exemplo, para a avaliação de políticas públicas, que requer foco específico de investigação e metodologia.

\section{REFERÊNCIAS}

ABRÚCIO, Fernando Luiz. A dinâmica federativa da educação brasileira: diagnóstico e propostas de aperfeiçoamento. In: OLIVEIRA, Romualdo Portela; SANTANA, Wagner (Org.). Educação e federalismo no Brasil: combater as desigualdades, garantir a diversidade. Brasília: UNESCO, 2010. p. 39-70. Disponível em:

<http://unesdoc.unesco.org/images/0018/001873/187336por.pdf>. Acesso em: 4 out. 2015.

BARDIN, Laurence. Análise de conteúdo. Lisboa: Edições 70, 2011.

CASTRILLÓN, Silvia. O direito de ler e de escrever. São Paulo: Pulo do Gato, 2011.

CESARINO, Maria Augusta da Nóbrega (Org.). Bibliotecas públicas municipais: orientações básicas. Belo Horizonte: Secretaria de Estado da Cultura, Superintendência de Bibliotecas Públicas, 2007.

CESARINO, Maria Augusta da Nóbrega. Biblioteca Pública Estadual Luiz de Bessa: 50 anos de cultura. Belo Horizonte: Secretaria de Estado da Cultura de Minas Gerais, Superintendência de Bibliotecas Públicas, 2006. 
CESARINO, Maria Augusta da Nóbrega. Construindo uma Minas

leitora: o retrato das bibliotecas públicas de Minas Gerais. Belo Horizonte: Secretaria de Estado de Cultura, Superintendência de Bibliotecas Públicas, 2008.

CESARINO, Maria Augusta da Nóbrega. Construindo uma Minas leitora: o retrato das bibliotecas públicas de Minas Gerais. Belo Horizonte: Secretaria de Estado de Cultura, Superintendência de Bibliotecas Públicas, 2014.

CUNHA, Murilo Bastos; CAVALCANTI, Cordélia Robalinho de Oliveira. Dicionário de biblioteconomia e arquivologia. Brasília: Briquet de Lemos, 2008.

FEDERAÇÃO INTERNACIONAL DE ASSOCIAÇÕES DE BIBLIOTECÁRIOS E BIBLIOTECAS - IFLA. Diretrizes da IFLA para bibliotecas públicas. Tradução de Antonio Agenor Briquet de Lemos. Brasília: Briquet de Lemos, 2012.

FONSECA, Edson Nery. Introdução à biblioteconomia. 2. ed. Brasília: Briquet de Lemos, 2007.

LEMOS, Carolina Siqueira. Gestão pública orientada para resultados: avaliando o caso de Minas Gerais. 2009. 128 f. Dissertação (Mestrado em Administração Pública) - Escola Brasileira de Administração Pública, Fundação Getúlio Vargas, Rio de Janeiro, 2009.

MACHADO, Elisa Campos. Análise de políticas públicas para bibliotecas no Brasil. InCID: Revista de Ciência da Informação e Documentação, Ribeirão Preto, v. 1, n. 1, p. 94-111, 2010. Disponível em: <http://www.revistas.usp.br/incid/article/view/42307/45978>. Acesso em: 10 abr. 2015.

MACHADO, Frederico Borges; SUAIDEN, Emir José. O papel da biblioteca pública e seus desafios frente aos avanços tecnológicos. In: CONGRESSO BRASILEIRO DE BIBLIOTECONOMIA, DOCUMENTO E CIÊNCIA DA INFORMAÇÃO, 25., 2013, Florianópolis. Anais...

Florianópolis: Federação Brasileira de Bibliotecários, Cientistas da Informação e Instituições, 2013. p. 764-799. Disponível em: <http://portal.febab.org.br/anais/article/view/1273>. Acesso em: 12 out. 2012.

MARTINS, Wilson. A palavra escrita: história do livro, da imprensa e da biblioteca. 3. ed. São Paulo: Ática, 2002.

MINAS GERAIS. Assembleia Legislativa. Políticas públicas. Disponível em <http://politicaspublicas.almg.gov.br/sobre/index.html\#O_que_e_monitor ar>. Acesso em: 1 set. 2015a. 
MINAS GERAIS. Lei no 1.087, de 02 de junho de 1954. Cria a biblioteca pública de Minas Gerais e dá outras providências. Disponível em:

<http://www.almg.gov.br/consulte/legislacao/completa/completa.html?tip o=LEI\&num=1087\&comp=\&ano=1954 > . acesso em: 1 set. 2015.

MINAS GERAIS. Lei no 11.714, de 26 de dezembro de 1994a. Dispõe sobre a reestruturação da Secretaria de Estado da Cultura e dá outras providências. Disponível em:

<http://www.almg.gov.br/consulte/legislacao/completa/completa.html?tip o=LEI\&num=11714\&comp=\&ano=1994>. Acesso em: 1 set. 2015.

MINAS GERAIS. Lei no 11.726, de 30 de dezembro de 1994b. Dispõe sobre a política cultural do Estado de Minas Gerais. Disponível em: $<$ http://www.siam.mg.gov.br/sla/download.pdf?idNorma=2292>. Acesso em: 1 set. 2015 .

MINAS GERAIS. Lei no 8.502, de 19 de dezembro de 1983. Altera a legislação tributária do Estado de Minas Gerais e dá outras providências. Disponível em:

<https://www.legisweb.com.br/legislacao/?id=139826>. Acesso em: 1 set. 2015.

MINAS GERAIS. Plano mineiro de desenvolvimento integrado. Disponível em:<http://seplag.mg.gov.br/estrategia-de-governo/planomineiro-de-desenvolvimento-integrado>. Acesso em: 1 set. 2015b.

MUELLER, Susana P. M. Bibliotecas e sociedade: evolução da interpretação de função e papéis da biblioteca. Revista da Escola de Biblioteconomia da UFMG, Belo Horizonte, v. 13, n. 1, p. 7-54, mar. 1984.

PAIVA, Marília de Abreu Martins. Bibliotecas públicas: políticas do estado brasileiro de 1990 a 2006. 2008. 144 f. Dissertação (Mestrado em Ciência da Informação) - Escola de Ciência da Informação, Universidade Federal de Minas Gerais, Belo Horizonte, 2008.

RUA, Maria das Graças; ROMANINI, Roberta. Tipologias e tipos de políticas públicas. In: . Para aprender políticas públicas.

Brasília: IGEPP, 2013. p. 48-54.Disponível em:

$<$ http://igepp.com.br/uploads/ebook/para_aprender_politicas_publicas__unidade_05.pdf >. Acesso em: 5 set. $20 \overline{15}$.

SARAIVA, Enrique. Introdução à análise de políticas públicas. In: SARAIVA, Enrique; FERRAREZI, Elisabete. Políticas públicas, coletânea. Brasília: ENAP, 2006. v. 1.

SILVA, Frederico A. Barbosa. Economia e política cultural: acesso, emprego e financiamento. Brasília: IPEA, 2007. 
SILVEIRA, Fabrício José Nascimento. Biblioteca pública, identidade e enraizamento: elaborações intersubjetivas ancoradas em torno da Luiz de Bessa. 2014. 253 f. Tese. (Doutorado em Ciência da Informação) Escola de Ciência da Informação, Universidade Federal de Minas Gerais, Belo Horizonte, 2014.

SOUZA, Celina. Políticas públicas: uma revisão da literatura.

Sociologias, Porto Alegre, ano 8, n. 16, p. 20-45, jul./dez. 2006. Disponível em: <http://www.scielo.br/pdf/soc/n16/a03n16>. Acesso em: 15 jan. 2015.

SUAIDEN, Emir José. A biblioteca pública no contexto da sociedade da informação. Ciência da Informação, Brasília, v. 29, n. 2, p. 52-60, maio/ago. 2000. Disponível em: <http://www.scielo.br/pdf/ci/v29n2/a07v29n2.pdf>. Acesso em: 20 jun. 2014.

UNESCO. Manifesto da Unesco para bibliotecas públicas. 1994.

Disponível em: <http://www.ifla.org/VII/s8/unesco/port.htm> Acesso em: 10 jun. 2007.

\title{
Title
}

Public Library: Minas Gerais' state policies (1983-2012)

\begin{abstract}
Introduction: This research aims to describe and analyze the policies for public libraries of Minas Gerais, aiming to understand the possible advances and retreats of these policies from 1983 to 2012. What justifies this research is that searching public libraries within the public policy context can serve as an important support for public managers to program new propositions, contributing to the study of the social role of information and cultural policies in the field of Information Science.

Objectives: Its specific objectives are to identify government policies for public libraries through legal acts and administrative documents; to understand the actual implementation of such policies through testimonials and to track possible progress or set backs provided by policies implemented for public libraries.

Methodology: The methodology used was documentary analysis, by means of the documents content analysis, and also carrying out semi-structured interviews with managers of the Minas Gerais Public Library Superintendence (direction).
\end{abstract}

Results: Data were classified into categories of analysis, namely: legal frameworks, network libraries, relationship between State and Union, relationship between State and each county, librarian role, training and events, communication, financing, State Policies and Government Policies and Book and Reading State Plan.

Conclusions: At the end, we found that policies for public libraries in Minas Gerais have advanced, although modestly, and that the history of policies 
already carried out are configured, greatly, as Government Policies, not as State Policies.

Keywords: Public Library. State policies. Minas Gerais.

\section{Titulo}

Bibliotecas públicas: Políticas del Estado de Minas Gerais

\section{Resumen}

Introducción: Describe y analiza las políticas para las bibliotecas públicas de Minas Gerais, para entender los posibles avances y retrocesos de estas políticas desde 1983 a 2012. Justificada esta investigación en que, buscando las bibliotecas públicas en el contexto de la política pública puede servir como un apoyo importante para los gestores públicos para programar nuevas acciones, lo que contribuye al estudio de la función social de las políticas de información y culturales en el campo Ciencia de la Información.

Objetivos: Sus objetivos son identificar las políticas públicas a las bibliotecas públicas a través de actos documentos legales y administrativos; conocer la aplicación real de estas políticas a través de entrevistas y rastrear posibles avances o retrocesos previstos por las políticas implementadas para las bibliotecas públicas.

Metodología: La metodología utilizada fue el análisis documental, a través de los documentos de análisis de contenido, así como la realización de entrevistas semi-estructuradas con los directores de la Superintendencia de Bibliotecas Públicas de Minas Gerais.

Resultados: Los datos fueron clasificados en categorías de análisis, a saber: los marcos jurídicos, las bibliotecas de la red, la relación entre lo estado e la Unión, la relación entre lo estado e los municipios, función bibliotecaria, formación y eventos, comunicación, financiación, políticas de Estado y Plan de Gobierno y Plano del Libro y de la Lectura del Estado.

Conclusiones: Al final, encontramos que las políticas de las bibliotecas públicas en Minas Gerais han avanzado, aunque tímidamente, y que la historia de las políticas ya realizadas se configuran, en gran medida, ya que las políticas del Gobierno, no como políticas de Estado.

Palavras clave: Biblioteca pública. Políticas públicas. Minas Gerais.

Recebido: 28.10.2015

Aceito: 09.04.2016 